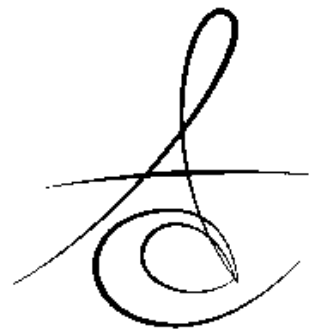

\title{
LAZER UYGULAMALARININ PROTEZ KAİDE TAMİRİNİN DAYANIMINA ETKİsí
}

\section{EFFECT OF LASER TREATMENTS ON THE STRENGTH OF DENTURE BASE REPAIR}

\author{
Yrd. Doç. Dr. Fatih Mehmet KORKMAZ* \\ Dr. Dt. Elif AYDOĞAN AYAZ* \\ Yrd. Doç. Dr. Sabit Melih ATES***
}

Doç. Dr. Bora BAĞIŞ**

Yrd. Doç. Dr. Sedanur TURGUT*

Doç. Dr. Tamer TUZUNER****

\begin{abstract}
Makale Kodu/Article code: 1247
Makale Gönderilme tarihi: 30.07.2013

Kabul Tarihi: 02.10 .2013
\end{abstract}

\section{ÖZET}

Amaç: Bu çalışmanın amacı, kumlama ve frezleme yapmadan önce değişik enerji seviyelerindeki Er;Cr;YSGG lazer uygulamasının otopolimerizan akrilin transvers dayanımına olan etkisini incelemektir.

Gereç ve Yöntem: Toplam 70 adet dikdörtgen şeklindeki örnekler (65X10X3.3 mm) ısıyla polimerize olan akrilik rezinden üretilmiştir. Bu örnekler aşağıdaki yüzey işlemlerinden birini takiben otopolimerizan akril ile tamir edilmiştir: a) Herhangi bir yüzey işlemi yapılmamış (kontrol), b) Frezleme, c) Kumlama, d) Er;Cr;YSGG lazer (3 W-20 Hz) + frezleme, e) Er;Cr; YSGG lazer (3 W-20 Hz) + kumlama, f) Er;Cr;YSGG lazer (4 W-20 Hz) + frezleme, g) Er;Cr;YSGG lazer (4 W-20 Hz) + kumlama. Transvers dayanımı universal test cihazında 3 nokta bükme testi kullanılarak ölçülmüştür. Elde edilen veriler tek yönlü ANOVA ve Tukey'in Post Hoc testi kullanılarak analiz edilmiştir.

Bulgular: Kumlama yapılmadan önce $4 \mathrm{~W}-20 \mathrm{~Hz}$ 'lik Er;Cr;YSGG lazer uygulaması (30.48 $77.66 \mathrm{MPa})$ kontrol grubuna (15.48土4.32 MPa) göre daha yüksek değerler oluşturmuştur. Frezleme, tüm gruplar içinde

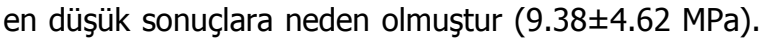
Kumlama işlemi, frezleme işleminden anlamlı bir şekilde yüksek bulunmuştur $(p<0.01) .4 \mathrm{~W}-20 \mathrm{~Hz}$ 'lik Er;Cr;YSGG lazer + kumlama uygulaması sadece kumlama yapılan gruba göre daha yüksek çıkmıştır.

Sonuçlar: Tamir yapmadan önce akrilik kaide rezin yüzeyine uygulanan ön işlemler tamir dayanımını etkilemektedir. Kumlamadan önce 4 W-20 Hz'lik $\mathrm{Er} ; \mathrm{Cr}$;YSGG lazer uygulaması akrilik rezinin tamir dayanımını arttırmada faydalı olabilir.

Anahtar kelimeler: protez tamiri, lazerler, akrilik rezin

\section{ABSTRACT}

Purpose: The aim of this study was to investigate the effect of Er;Cr;YSGG laser treatment with different energy levels before sandblasting and grinding on the transverse strength of denture base resin repaired with autopolymerizing resin.

Material and Methods: A total of seventy rectangular specimens $(65 \times 10 \times 3.3 \mathrm{~mm})$ were prepared from heatpolymerized acrylic resin, which was repaired with autopolymerizing resin following conditioning methods: a) without surface treatment (control) b) grinding, c) sandblasting, d) $\mathrm{Er} ; \mathrm{Cr}$; YSGG laser at $3 \mathrm{~W}-20 \mathrm{~Hz}+$ grinding, e) $\mathrm{Er} ; \mathrm{Cr}$; YSGG laser at $3 \mathrm{~W}-20 \mathrm{~Hz}+$ sandblasting, f) $\mathrm{Er} ; \mathrm{Cr}$;YSGG laser at $4 \mathrm{~W}-20 \mathrm{~Hz}+$ grinding, g) $\mathrm{Er} ; \mathrm{Cr}$; YSGG laser at $4 \mathrm{~W}-20 \mathrm{~Hz}+$ sandblasting. The transvers strength was measured by a three-point bending test using a universal testing machine. Data were analyzed using 1-way ANOVA and Tukey's Post Hoc test $(p<0.05)$.

Results: $\mathrm{Er} ; \mathrm{Cr}$;YSGG laser application at $4 \mathrm{~W}-2 \mathrm{OHz}$ before sandblasting occured significantly higher values (30.48 $\pm 7.66 \mathrm{MPa}$ ) when compared to the control group $(15.48 \pm 4.32 \mathrm{MPa})(p<0.001)$. Grinding demonstrated the lowest values $(9.38 \pm 4.62 \mathrm{MPa})$ among all the groups. Sandblasting showed significantly higher values than grinding $(p<0.01)$. Laser application at $4 \mathrm{~W}-20 \mathrm{~Hz}+$ sandblasting demonstrated significantly higher strength values than sandblasting alone $(p<0.05)$.

Conclusions: Surface pretreatments before repairing significantly affect the transvers strength of repaired denture base resin. $\mathrm{Er} ; \mathrm{Cr} ; \mathrm{YSGG}$ laser pretreatment at 4 $\mathrm{W}-2 \mathrm{~Hz}$ before sandblasting may be useful to increase the transvers strength of denture base repairs.

Key words: denture repair, lasers, acrylic resin

\footnotetext{
* Karadeniz Teknik Üniversitesi, Diş Hekimliği Fakültesi, Protetik Diş Tedavisi A.D.,Trabzon

** İzmir Katip Çelebi Üniversitesi, Diş Hekimliği Fakültesi, Protetik Diş Tedavisi A.D.,İzmir

*** Recep Tayyip Erdoğan Üniversitesi, Diş Hekimliği Fakültesi, Protetik Diş Tedavisi A.D.,Rize

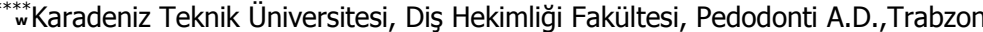




\section{GİRİş}

Protez kaide materyali olarak kullanılan akrilik rezinler çalışma şartlarının uygun olması, estetik ve ekonomik olmaları gibi avantajlarının yanı sıra zayıf yorulma ve çarpma dayanımına sahip olmaları en büyük dezavantajlarıdır. ${ }^{1}$ Akrilik rezinden hazırlanmış tam protezler bir süre klinik kullanımlarından sonra kırık oluşmaya yatkın hale gelirler. ${ }^{2}$ Eski protezlerin uzun yıllar kullanılabilmesi veya yeni yapılacak proteze kadar hastanın protezsiz kalmaması için protez tamiri sıklıkla uygulanmaktadır.,4 Akrilik rezin kırıklarının tamirinde tamir materyalinin seçimi de klinisyenler için önemli bir konudur., ${ }^{3,5}$ Tamir materyalinin seçimi; tamir için gereken zamana, tamirin transvers dayanımına ve tamir materyalinin boyutsal doğruluğuna bağlı olarak değişmektedir. ${ }^{5-7}$

Otopolimerizan akrilik rezin, protez kırıklarının tamirinde en çok kullanılan malzemelerden bir tanesidir. Akrilik protez, otopolimerizan akril ile tamir edildiğinde karşılaşılan en büyük sorun tamirin orijinal protezden daha dayanıksız olması ve kısa bir süre sonra yeniden kırılmasıdır. ${ }^{8}$ Genellikle ikincil kırıklar tamir materyali ile kaide arasında ve muhtemel zayıf adezyona bağı olarak gerçekleşmektedir. ${ }^{7-9}$ Akrilik rezin, otopolimerizan akril ile tamir edildiğinde yeniden kırılmaması için yeterli tamir dayanımına sahip olması gerekir. ${ }^{2}$ Akril tamirindeki başarı tamir kenarlarının yüzey şekline, tamir şekline ve tamirden önce tamir yüzeyine uygulanan işlemlere bağlıdır. ${ }^{8,10,11}$ Hiçbir tamir işlemi orijinal akrilin dayanımına yakın dayanıma sahip olmasa da kırık yüzey üzerine uygulanabilecek çeşitli mekanik ve kimyasal ön işlemlerin yüzey morfolojisini veya kimyasını değiştirerek daha iyi bağlantı sağlayabildikleri çeşitli araştırmalarda gösterilmiştir., ${ }^{811-16}$ Böylelikle tamir materyali ile kırık yüzeyi arasında oluşturulabilecek güçlü bağlantı tamirin ömrünü uzatabilmektedir. ${ }^{8,10,17}$ Akrilik rezinin yüzey alanını arttırarak daha iyi bağlantı sağlayabilmek için kumlama, frezleme ve lazer ile pürüzlendirme işlemeleri uygulanabilmektedir. ${ }^{18-25}$

Daha önce yapılan çalışmalarda akrilik rezin yüzeyine yapılan mekanik yüzey işlemlerinin bağlantı gücünü etkilediği gösterilmiştir. 3,6,20,21,26-28 Minami ve arkadaşları $^{3}$ da yaptıkları çalışmada, mekanik ve kimyasal yüzey işlemlerinin akrilin tamir dayanımını arttırdığını göstermişlerdir. Pereira ve arkadaşları ${ }^{6}$ ise yüzeyi metil metakrilatla ıslatmanın tamir dayanımını arttırdığını ancak yüzeyi mekanik olarak zımparalamanın tamir dayanımını arttıramadığını göstermişlerdir. Katsumata ve arkadaşları'nın ${ }^{28}$ yaptıkları çalışmada, akrilik rezin yüzeyine Rocatec uygulamanın naylon protez kaide polimerinin otopolimerize akril ile yapılan tamirin dayanımını arttırdığını göstermişlerdir. Storer ve arkadaşları'nın ${ }^{26}$ yaptıkları çalışmada, akrilik rezin yüzeyini kumlamanın yumuşak astarın bağlantı gücünü arttırdığını göstermiştir. Ancak Jacobsen ve arkadaş$\mid a r{ }^{21}$ yüzeye lazer uygulamasının veya kumlama yapılmasının bağlantıyı azalttığını göstermişlerdir. Literatür incelemesinde akrilik rezin tamiri için hala önerilen net bir uygulama yöntemi yoktur.

Son yıllarda kullanımı giderek yaygınlaşan sert doku lazerleri, mine ve dentin aşındırılması, kemik operasyonları, kavite hazırlanması, kanal genişletme ve yüzey pürüzlendirmesi gibi alanlarda kullanılmaktadır. $^{29,30} \mathrm{Er}, \mathrm{Cr}$;YSGG lazer sistemi (Waterlase MD Turbo, Biolase Technology Inc., San Clemente, ABD) $2.78 \mathrm{~nm}$ dalga boyuna sahiptir ve su taneciklerini atomize hale getirerek doku yüzeyinde lazer enerjisiyle birleştirmektedir. Bu sayede etki çok daha güçlü olmaktadır. ${ }^{31,32} \mathrm{Er}, \mathrm{Cr}$;YSGG lazer sistemi hava ve su ile birlikte kullanıldığı için dokuda ISı artışına neden olmamaktadır. ${ }^{29,32} \mathrm{Bu}$ yönüyle de sert dokularda güvenli bir şekilde kullanılabilmektedir. ${ }^{29,32} \mathrm{Er}, \mathrm{Cr}$; YSGG lazerin sert dokularda, mine ve dentin yüzeylerinde pürüzlendirmek amacıyla kullanımı pek çok araştırmaya konu olmuştur. ${ }^{29-34}$ Yine literatüre bakıldığında Er:YAG, Nd:YAG, KTP ve $\mathrm{CO}_{2}$ lazerlerin akrilik rezin yüzeyini pürüzlendirmek amacıyla kullanıldığı birçok araştırma olmasına rağmen, ${ }^{20-25} \mathrm{Er}, \mathrm{Cr}$;YSGG lazerin akrilik rezin tamirinde yüzey işlemi olarak kullanıldığı çalışmanın çok az olduğu görülmektedir.

$\mathrm{Bu}$ çalışmanın amacı; kumlama ve frezleme gibi mekanik yüzey işlemlerinden sonra değişik enerji seviyelerineki $\mathrm{Er}, \mathrm{Cr}$;YSGG lazer uygulamasının otopolimerizan akrille yapılan tamirin transvers dayanıma olan etkisini araştırmaktır. Çalışmanın hipotezi; mekanik yüzey işlemlerinden sonra lazer ile pürüzlendirmenin otopolimerizan akrilin tamir dayanımını etkilemeyeceği şeklindedir.

\section{MATERYAL VE METOD}

Çalışmamızda akrilik blokların elde edilmesi amacıyla $65 \times 10 \times 3.3 \mathrm{~mm}$ boyutlarındaki (ISO 1567) ${ }^{35}$ mum örnekler standart paslanmaz çelik kalıp kullanılarak üretilmiştir. Her bir deneysel grup için 10 
adet olmak üzere toplam 70 adet mum örnek hazırlanmıştır. Daha sonra mum örnekler bilinen usullerle muflalanarak akril tepimine hazır hale getirilmiştir. Muflalar açılıp elde edilen boşluklara Isı ile polimerize olan akrilik rezin (QC-20, Dentsply Ltd, Addlestone, Birleşik Krallık) hamuru yerleştirilmiş ve üreticinin önerileri doğrultusunda polimerize edilmiştir. Polimerize olan örnekler muflalardan çıkartılarak yüzeylerindeki düzensizliklerin giderilmesi amacıyla sırasıyla 200, 400, 600 gridlik su zımparası ile zımparalanmıştır. Daha sonra tüm örnekler distile suda $37^{\circ} \mathrm{C}^{\prime}$ de 1 hafta bekletilmiştir. Bu örnekler, 3mm'lik bir kırık hattı oluşturmak için kalınlığı 3mm olan elmas disk (KG Sorensen, Sao Paulo, Brezilya) kullanılarak ortadan ikiye ayrımıştır. Örneklerin kırık hatları butt joint bitim şeklinde yuvarlatılmış ve bu yüzeyler 600 grid'lik su zımparası ile düzeltilmiştir. Daha sonra örnekler ultrasonik temizleyicide distile su ile temizlenmiş ve basınçlı hava ile kırık yüzeyleri kurutulmuştur. Yüzeyleri düzeltilip temizlenen örnekler yapılacak yüzey işlemlerine göre rastgele 7 gruba ayrılarak aşağıdaki yüzey işlemleri yapılmıştır $(n=10)$.

Grup 1: Herhangi bir yüzey işlemi uygulanmamış (kontrol)

Grup 2: Frez ile pürüzlendirme

Grup 3: Alüminyum oksit ile kumlama (Resim 1)

Grup 4: Er;Cr;YSGG lazer (3 W-20 Hz) + frezleme

Grup 5: Er;Cr;YSGG lazer $(3 \mathrm{~W}-20 \mathrm{~Hz})$ + alüminyum oksit ile kumlama

Grup 6: Er;Cr;YSGG lazer $(4 \mathrm{~W}-20 \mathrm{~Hz})$ + frezleme

Grup 7: Er;Cr;YSGG lazer (4 W-20 Hz) + alüminyum oksit ile kumlama (Resim 2)

Frezleme işleminde örnekler bir mengeneye tutturulduktan sonra tungsten karbid frez ile (Axis Dental University, Cutter uc 251 E5, Coppell, Texas, $A B D$ ) hafif basınç altında aralıklı temas sağlanacak şekilde düşük devirde su soğutmalı olarak pürüzlendirilmiştir. ${ }^{34}$ Kumlama işlemi de örneklerin 50 رm'lik alüminyum oksit partikülleriyle 0,5 $\mathrm{MPa}$ basınç altında 5 saniye pürüzlendirilmesiyle gerçekleştirilmiştir. Lazer ile pürüzlendirme işleminde Er;Cr;YSGG lazer kullanılmıştır. Lazer cihazının dalga boyu $2.780 \mathrm{~nm}$, pulsasyon süresi 140-200 $\mu \mathrm{s}$, uygulamadaki atım sıklığı $20 \mathrm{~Hz}$, atım gücü çalışma grubuna göre $3 \mathrm{~W}$ (150 mJ/Pulse) veya $4 \mathrm{~W}$ (200 mJ/Pulse) olarak ayarlanmıştır. Tüm lazer gruplarında hava-su spreyinin derecesi \% 85 hava ve \% 85 su olacak şekilde ayarlanırken lazer; 6 mm uzunluğunda $600 \mu \mathrm{m}$ çapında safir uç (MG6) kullanılarak uygulanmıştır. İşlem sırasında lazer ucunun örnek yüzeyinden $1 \mathrm{~mm}$ uzaklıkta yüzeye dik olacak şekilde fokus moda konumlanmasına özen gösterilmiştir (Resim 3).

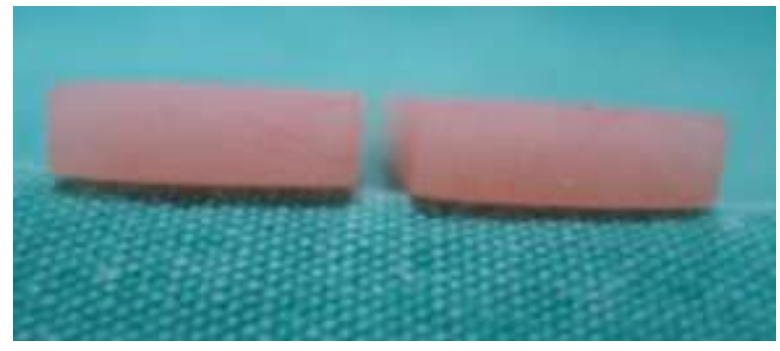

Resim 1. Alüminyum oksit ile kumlanmış akrilik rezinin tamir yüzeyi

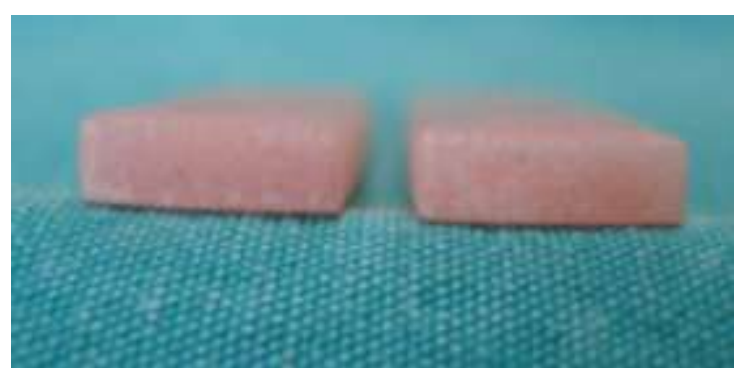

Resim 2. Er;Cr; YSGG lazer (4 W-20 Hz) ile pürüzlendirildikten sonra alüminyum oksit ile kumlanmış akrilik rezinin tamir yüzeyi

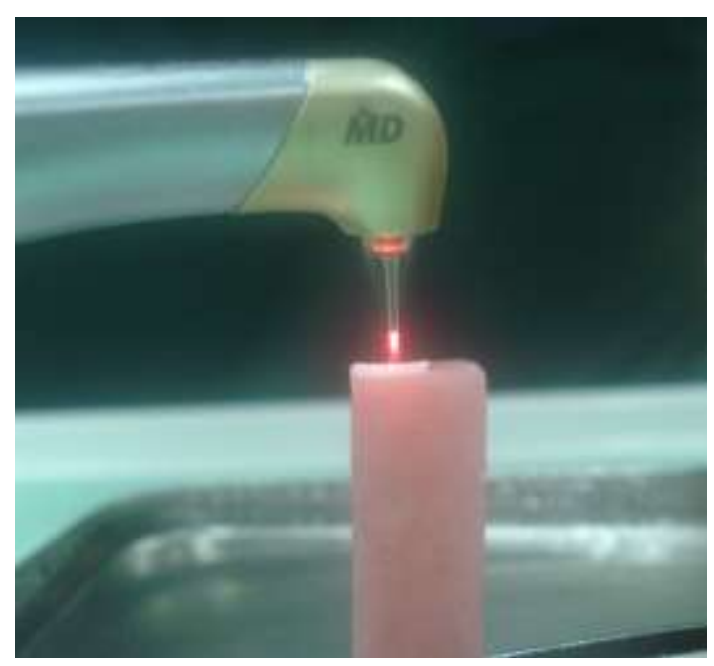

Resim 3. Er;Cr;YSGG lazer ile pürüzlendirme işleminin görüntüsü. 
Yüzey işlemleri yapıldıktan sonra örnekler yine ultrasonik temizleyicide distile su ile temizlenmiş ve basınçlı hava ile kurutulmuştur. Daha sonra akrilik örnekler her iki örneğin arasında 3 mm'lik boşluk olacak şekilde mufladaki yerlerine tekrar yerleştirilmiştir. Otopolimerizan akrilik rezin (Meliodent, Heraeus Kulzer Ltd, Newbury, Birleşik Krallık) üreticinin tavsiyesine göre hazırlanıp polimerizasyon büzülmesini kompanze etmek ve bitim işlemlerine imkan sağlamak için bu boşluklara biraz fazla olacak şekilde tepilmiştir. Otopolimerizan akrilik rezinin polimerizasyonu 2.2 bar basınç altında $45^{\circ} \mathrm{C}^{\prime}$ de 10 dakika tutularak gerçekleşmiştir. Kenarları 600 grid'lik su zımparası ile düzeltilen örnekler mekanik test öncesi $37{ }^{\circ} \mathrm{C}^{\prime}$ lik distile suda 48 saat bekletilmiştir.

Örneklerin transvers dayanımı 3 nokta bükme testi kullanılarak universal test cihazında (Universal Testing Machine, Lloyd, Instruments, LRx, Fareham Hant, Birleşik Krallık) ölçülmüştür. Test gerçekleştirilirken örnek yerleştirilecek olan metal destekler arası uzaklık $50 \mathrm{~mm}$, uygulanacak yük $100 \mathrm{kgf}$ ve kırma hızı $5 \mathrm{~mm} / \mathrm{dk}$ olacak şekilde ayarlanıp örneğin tam ortasına dik yönlü kuvvet uygulanmıştır. Yük uygulaması örnek kırıana kadar devam etmiş ve kırıma anında en yüksek değerler cihazın bilgisayar sistemine otomatik olarak kaydedilmiştir. Transvers dayanıklılık değerleri de aşağıdaki formüle göre hesaplanmıştı: ${ }^{8}$

$\mathrm{S}=3 \mathrm{FL} / 2 \mathrm{bd} \mathrm{d}^{2}$

$\mathrm{S}=$ Transvers dayanıklılık $\left(\mathrm{N} / \mathrm{mm}^{2}\right)$

F: Kırılma anındaki yük (N)

L: Destekler arası uzaklık (mm)

b: Örnek genişliği (mm)

d: Örnek kalınlı̆ı $(\mathrm{mm})$

Çalışma verilerinin istatistiksel olarak değerlendirilmesi SPPS, Windows 15.0 programı kullanılarak, tek yönlü ANOVA ve Tukey'in Post Hoc testi ile \% 95 güven aralığında gerçekleştirilmiştir.

\section{BULGULAR}

Her gruba ait örneklerin transvers dayanımının ortalama, standart sapma, minimum ve maksimum değerleri Tablo 1'de gösterilmiştir. En yüksek transvers dayanımı Er;Cr;YSGG lazer (4 W-20 Hz) + kumlama grubunda (Grup 7) $30,49 \pm 7,66 \mathrm{MPa}$ olarak tespit edilirken en düşük değerler ise yalnızca frez ile pürüzlendirilmiş grupta (Grup 2) $9.38 \pm 4.62 \mathrm{MPa}$ olarak tespit edilmiştir. Grup 7 ortalama değer olarak, Grup 5 hariç diğer tüm gruplardan istatistiksel olarak fark yaratacak şekilde yüksek bulunmuştur. Grup 7'de elde edilen sonuçlar Grup 5'ten yüksek olmasına rağmen bu fark istatistiksel olarak anlamlı bulunmamışırı. Grup 2'nin sonuçları kontrol grubuna göre düşük tespit edilmesine rağmen bu fark istatistiksel olarak anlamlı bulunmamışıı. Grup 3'nin transvers dayanımı Grup 2'den yüksek bulunurken $(p=0.0049)$, Grup 7'nin transvers dayanımı Grup 3'ten yüksek bulunmuştur. Frezleme yapılmış örneklere lazer uygulaması transvers dayanımını artırmış ancak bu artış istatistiksel olarak anlamlı bulunmamıştır.

Tablo 1. Örneklerin transvers dayanıklılık değerleri (MPa)

\begin{tabular}{|l|l|}
\hline Gruplar & $\begin{array}{c}\text { Ort } \pm \text { SS } \\
\text { (min, maks) }\end{array}$ \\
\hline Grup 1 & $\begin{array}{l}15.48 \pm 4.32^{\mathrm{A}} \\
(9.40,25.04)\end{array}$ \\
\hline Grup 2 & $9.38 \pm 4.62^{\mathrm{A}}$ \\
& $(4.50,16.57)$ \\
\hline Grup 3 & $20.79 \pm 9.03^{\mathrm{B}, \mathrm{A}}$ \\
& $(8.11,33.68)$ \\
\hline Grup 4 & $16.90 \pm 5.55^{\mathrm{B}, \mathrm{A}}$ \\
\hline & $(8.14,24.10)$ \\
\hline Grup 5 & $22.43 \pm 5.34^{\mathrm{B}, \mathrm{C}, \mathrm{A}}$ \\
\hline & $(13.89,31.14)$ \\
\hline Grup 6 & $17.46 \pm 7.95^{\mathrm{B}, \mathrm{A}}$ \\
\hline & $(8.09,31.80)$ \\
\hline Grup 7 & $30.48 \pm 7.66^{\mathrm{C}}$ \\
\hline Üst simge & $(16.62,40.82)$ \\
\hline
\end{tabular}

* Üst simge olarak kullanılan farklı büyük harfler gruplar arasında $p<0.05$ düzeyindeki istatistiksel farkı göstermektedir.

Ort: ortalama SS: standart sapma

\section{TARTIŞMA}

Bu araştırmada kumlama ve frezleme gibi mekanik yüzey işlemlerine ilaveten değişik enerji seviyelerindeki $\mathrm{Er} ; \mathrm{Cr} ; \mathrm{YSGG}$ lazer uygulamalarının akrilik rezinin tamir dayanımına olan etkisi incelenmiştir. Çalş̧ma sonucunda akrilik rezinin otopolimerizan akril ile tamirinde kumlama gibi mekanik işlemlerden önce $4 \mathrm{~W}$-20 Hz'lik Er;Cr;YSGG lazer uygulamasının tamir dayanımını arttırmada faydalı olabileceği tespit edilerek hipotezimiz kısmen reddedilmiştir.

Tamir edilmiş akrilik rezinlerde en çok karşılaşılan başarısızlıklardan birisi de transvers başarısızlıklardır. ${ }^{13}$ Bu yüzden çalışmamızda akrilik rezinin tamir dayanımını tespit etmek için 3 nokta bükme testi kullanılmışır. 
Daha önce yapılan çalışmalar göstermiştir ki tamir edilen akrilik kaide rezinin transvers dayanımı, orjinal haline göre daha düşüktür. ${ }^{6,8,11,12} \mathrm{Bu}$ düşüşün nedeninin akrilik kaide rezini ile tamir rezini arasındaki zayıf bağlantıdan olabileceği vurgulanmıştır. ${ }^{8}$ Materyallerin yüzey enerjisi yüzey geometrisine bağlıdır ve yüzey işlemlerinden etkilenmektedir. ${ }^{21,36}$ Yüzey pürüzlülüğünün artması hem bağlantı yüzeyini, hem de yüzey enerjisini artırmaktadır. ${ }^{12,17,19,21}$ Yüzey enerjisinin artması van der Walls çekiminin artmasını sağlamış bu sayede bağlantı gücü de artmıştır. ${ }^{12,17,19,21}$ Akrilik kaide rezinlerin tamir yüzeylerinin pürüzlendirilmesiyle tamir dayanımının arttığı genellikle kabul edilen bir gerçektir. ${ }^{12}$ Bazı araştırıcılar tamir işleminden önce akrilik kaide rezin yüzeyinin $50 \mu m^{\prime}$ lik alüminyum oksit partikülleriyle kumlanmasının otopolimerizan akrilin kaideye olan bağlantısını arttırdığını tespit etmişlerdir. $^{3,18}$ Gulve ve arkadaşları $^{12}$ yaptıkları çalışmada, tamir yüzeyine uygulanan mekanik ve kimyasal yüzey işlemlerin otopolimerizan akril ile yapılan tamirin transvers dayanımını arttırdığını göstermişlerdir. Çalışmamızda kumlama işlemi kontrol grubuna göre transvers dayanımı arttırmış olsa da bu artış istatistiksel olarak anlamlı tespit edilmemiştir. Kumlama ile yüzey pürüzlülüğü artmasına rağmen yüzeyde gömülü olarak kalmış olabilecek alüminyum oksit taneleri bağlantıyı bozmuş, transvers dayanımı azaltmış olabilir. Ayrıca otopolimerizan akrilik rezinin visközitesinin yüksek olup kumlama ile elde edilen mikro çukurcuklara akamamış olması da bu sonuca etki eden bir diğer faktör olabilir. Frezleme işlemi ile elde edilen değerler kontrol grubuna göre daha düşük bulunsa da yine bu düşüş istatistiksel olarak anlamlı bulunmamıştır. Frezleme ile akril yüzey enerjisinin ve yüzey pürüzlülüğünün artmasına rağmen elde edilen pürüzlülük yüzeyde derin girinti ve çıkıntılar oluşturabildiğinden derin noktalara akan otopolimerizan akril dirençsiz kalıp transvers dayanımı azaltmış olabilir. Ayrıca derin ve homojen olmayan düzensizlikten kaynaklanan yüzeydeki stres birikimi soğuk akrilin akmasını ve yüzeyi ıslatmasını engelleyerek bağlantıyı olumsuz etkilemiş olabilir. ${ }^{25,37}$ Jacobsen ve arkadaşları ${ }^{21}$ kumlama ve $\mathrm{CO}_{2}$ lazer ile pürüzlendirme gibi yüzey işlemlerinin yumuşak astarın akrilik rezine olan bağlantısını inceledikleri çalışmada kontrol grubuyla kıyaslandığında kumlama ve lazer işlemlerinin bağlantı gücünü azalttığını tespit etmişlerdir. Yine bazı araştırmacılar yaptıkları çalışmalarda yumuşak astar uygulamadan önce yüzeyi kumlamanın bağlantıya etkisinin çok az olduğunu tespit edilmişlerdir. ${ }^{23,37}$

Yapılan bir çalışmada akril yüzeyine lazer uygulamasının yüzey pürüzlülüğünü $1.95 \mu$ m'den 2.22 $\mu$ m'ye çıkartarak üzerine uygulanan sıvı ile olan temas açısını azalttığı gösterilmiştir. ${ }^{38}$ Literatüre bakıldığında farklı lazerlerin akrilik rezinin yüzeyini pürüzlendirmede kullanıldığı birçok çalışma olmasına rağmen, ${ }^{20-25,38}$ bu çalışmaların sonuçlarının farklılık gösterdiği göze çarpmaktadır. Bazı araştırıcılar lazer uygulamasının akrilik rezin yüzeyinde büyük değişiklikler yapmasına rağmen yumuşak astarın akrilik rezine olan bağlantısını arttırmadığını göstermişlerdir. Ancak Tugut ve arkadaşları ${ }^{22}$ yumuşak astar uygulamadan önce değişik enerji seviyelerinde Er:YAG lazer uygulamasının yumuşak astar ile akrilik kaide arasındaki bağlantıya etkisini inceledikleri çalışmalarında bizim çalışmamızın sonuçlarına benzer şekilde lazer uygulamasının bağlantıyı arttırdığını tespit etmişlerdir. Bu çalışmalardaki sonuçların farklılığı değişik tipteki lazerlerin değişik enerji seviyelerinde uygulanmış ol- ması ve kullanılan akrilik rezinlerin farklı tipte olmasına dayandırılabilir.

Mevcut çalışmada yüzey pürüzlülüğünü arttırmak için kumlama ve frezleme işlemlerinden önce lazer uygulamaları kullanılmıştır. $\mathrm{Bu}$ çalışmanın sonucunda; kumlamadan önce akrilik kaide rezin yüzeyinin 4 W-20 Hz'lik Er;Cr;YSGG lazer ile pürüzlendirmenin otopolimerizan akrilin tamir dayanımını arttırdığı bulunmuştur $(p<0.001)$. Kumlamadan önce lazer ile yüzeyin pürüzlendirilmesi yüzeyde derin ve homojen olmayan düzensizlikler oluşturmuş ancak daha sonra yapılan kumlama işlemi ise tüm bu düzensizlikleri giderip yüzey enerjisini değiştirerek bağlantı için çok daha elverişli homojen bir pürüzlülük sağlamış olabilir. Çalışmamızda farklı enerji seviyelerindeki lazer uygulamaları farklı sonuçlar doğurmuştur. Bu sonuç diğer benzer çalışmalarla benzerlik göstermektedir. ${ }^{22,38}$ Bizim çalışmamızda 4 W (200 mJ/atım)-20 Hz'lik Er;Cr;YSGG lazer uygulaması 3W (200 mJ/atım)-20 Hz'lik lazer uygulamasına göre tüm gruplarda daha iyi sonuçlar doğurmuştur. Bu durum Er;Cr;YSGG lazerin yüksek enerjisi ile izah edilebilir. Daha yüksek enerji, yoğun hacimsel genleşmeyle beraber suyun ani buharlaşmasına neden olmuş olabilir. $^{39} \mathrm{Bu}$ hacimsel genleşme de yüzeydeki materyalin oluşan çukurcuklara akmasını ve daha iyi tutunmasını sağlamış olabilir. 
Bu çalışmanın limitleri ısısal yükleme altında çeşitli yaşlandırma işlemlerinin yapılmaması ve daha karmaşık protezler yerine basit dikdörtgen şeklindeki örneklerin kullanılmasıdır.

\section{SONUÇLAR}

1. Otopolimerizan akril ile tamir yapmadan önce akrilik kaide rezinin yüzeyinin çeşitli yöntemlerle pürüzlendirilmesi tamir dayanımını etkilemektedir.

2. Tamir işleminden önce, kumlama gibi mekanik işlemlerden önce $4 \mathrm{~W}-20 \mathrm{~Hz}$ 'lik $\mathrm{Er}$; $\mathrm{Cr}$; YSGG lazer uygulaması tamir dayanımını arttırmada faydalı olabilir.

\section{KAYNAKLAR}

1. Doğan A, Karacaer Ö, Doğan OM, Bolayır G, Bek B. Değişik polimerizasyon yöntemlerinin farkı konsantrasyonlarda cam fiberle güçlendirilen poli (metil metakrilat) protez kaide rezininin transvers dayanımına etkisi. Cumhuriyet Üniv Diş Hek Fak Derg 2007; 10:20-5.

2. Vallittu PK, Lassila VP, Lappalainen R.Wetting the repair surface with methyl methacrylate affects the transverse strength of repaired heat-polymerized resin. J Prosthet Dent 1994;72:639-43.

3. Minami $H$, Suzuki $S$, Minesaki $Y$, Kurashige $H$, Tanaka T. In vitro evaluation of the influence of repairing condition of denture base resin on the bonding of autopolymerizing resins. J Prosthet Dent 2004;91:164-70.

4. Sarac $D$, Sarac YS, Külünk Ş, Külünk $T$, Ural Ç. Farklı sürelerde metilen klorid uygulamasının otopolimerizan akrilin kaide materyaline bağlanma dayancı üzerine etkisi. Gazi Üniv Diş Hek Fak Derg 2005; 22: 157-61.

5. Dinçkal N, Aladağ Lì. Tamir edilmiş akriliklerin kırılma direnci üzerine tamir materyalinin, kırık yüzey şeklinin ve saklama ortamının etkisinin incelenmesi. Atatürk Üniv Dis Hek Fak Derg 1996;6:31-6

6. Pereira Rde $P$, Delfino CS, Butignon LE, Vaz MA, Arioli-Filho $\mathrm{JN}$. Influence of surface treatments on the flexural strength of denture base repair. Gerodontology 2012;29:234-8.

7. Seo RS, Neppelenbroek KH, Filho JNA. Factors affecting the strength of denture repairs. J Prosthodont 2007;16:302-10.
8. Elhadiry SS, Yunus N, Ariffin YT. Effect of cavity preparation on the flexural strengths of acrylic resin repairs. J Appl Oral Sci 2010;18:546-50.

9. Aladağ Lì, Yılmaz A. Fiber ile güçlendirilmiş kompozit rezin ve geleneksel tamir materyalleriyle tamir edilen akrilik rezinlerin dirençlerinin incelenmesi. Atatürk Üniv Dis Hek Fak Derg 2001;11:8-13.

10. Keyf F, Uzun G. The effect of glass fibrereinforcement on the transverse strength, deflection and modulus of elasticity of repaired acrylic resins. Int Dent J 2000;50:93-7.

11. Bural C, Bayraktar G, Aydin I, Yusufoğlu I, Uyumaz $N$, Hanzade M. Flexural properties of repaired heat-polymerising acrylic resin after wetting with monomer and acetone. Gerodontology 2010;27:217-23.

12. Gulve M, Gulve N. Effect of joint surface treatment on the flexural strength of repaired auyopolymerized acrylic resin. The Int J Dent Sci 2011;9: Dol:10.5580/2123

13. Thunyakitpisal $N$, Thunyakitpisal $P$, Wiwatwarapan C. The effect of chemical surface treatments on the flexural strength of repaired acrylic denture base resin. J Prosthodont 2011;20:195-9.

14. Vallittu PK, Lassila VP, Lappalainen R. Wetting the repair surface with methyl methacrylate affects the transverse strength of repaired heat-polymerized resin. J Prosthet Dent 1994;72:639-43.

15. Sarac YS, Sarac D, Kulunk T, Kulunk S. The effect of chemical surface treatments of different denture base resins on the shear bond strength of denture repair. J Prosthet Dent 2005;94:259-66

16. Pereira R de P, Delfino CS, Butignon LE, Vaz MA, Arioli-Filho $\mathrm{JN}$. Influence of surface treatments on the flexural strength of denture base repair. Gerodontology 2012;29:234-8.

17. Shen C, Colaizzi FA, Birns B. Strength of denture repairs as influenced by surface treatment. J Prosthet Dent 1984;52:844-8.

18. Memarian M, Shayestehmajd M. The effect of chemical and mechanical treatment of the denture base resin surface on the shear bond strength of denture repairs. Rev Clin Pesq Odontol 2009;5:117.

19. Jagger RG, al-Athel MS, Jagger DC, Vowles RW. Some variables influencing the bond strength 
between PMMA and a silicone denture lining material. Int J Prosthodont 2002;15:55-8.

20. Usumez A, Inan O, Aykent F. Bond strength of a silicone lining material to alumina abraded and lased denture resin. J Biomed Mater Res B Appl Biomater 2004;71:196-200.

21. Jacobsen NL, Mitchell DL, Johnson DL, Holt RA. Lased and sandblasted denture base surface preparations affecting resilient liner bonding. J Prosthet Dent 1997;78:153-8.

22. Tugut $F$, Akin $H$, Mutaf $B$, Akin GE, Ozdemir AK. Strength of the bond between a silicone lining material and denture resin after Er:YAG laser treatments with different pulse durations and levels of energy. Lasers Med Sci 2012;27:281-5.

23. Akin $H$, Tugut $F$, Mutaf $B$, Akin $G$, Ozdemir AK. Effect of different surface treatments on tensile bond strength of silicone-based soft denture liner. Lasers Med Sci 2011;26:783-8.

24. Süske $E$, Scharf $T$, Schaaf $P$, Panchenko $E$, Nelke $D$, Buback M, Kijewski $H$, Krebs HU. Variation of mechanical properties of pulsed laser deposited PMMA films during annealing, Appl Phys A 2004;79;1295-7.

25. Bolayir G, Turgut M, Hubbezoglu I, Dogan OM, Keskin S, Dogan A, Bek B. Evaluation of laser treatment on reline-base composites. J Adhesion 2007;83:117-27.

26. Storer R. Resilient denture base materials. Part 1, introduction and laboratory evalution. $\mathrm{Br}$ Dent $\mathrm{J}$ 1962;113:195-203.

27. Craig RG, Gibbons P. Properties of resilient denture liners. J Am Dent Assoc 1961;63:382-90.

28. Katsumata $Y$, Hojo S, Hamano N, Watanabe $T$, Yamaguchi $H$, Okada S, Teranaka T, Ino S. Bonding strength of autopolymerizing resin to nylon denture base polymer. Dent Mater J 2009;28:409-18.

29. Lin S, Caputo AA, Eversole LR, Rizoiu I. Topographical characteristics and shear bond strength of tooth surfaces cut with a laser-powered hydrokinetic system. J Prosthet Dent 1999;82:451-5.

30. Baygin $O$, Korkmaz FM, Tüzüner $T$, Tanriver $M$. The effect of different enamel surface treatments on the microleakage of fissure sealants. Lasers Med Sci 2012;27:153-60.

31. Usumez A, Aykent F. Farklı asitler ve Er, Cr: YSGG lazer sistemi ile pürüzlendirilen diş yüzeylerine uygulanan porselen laminate veneerlerin makaslama bağlantılarının karşılaştıııması. T Klin J Dental Sci 2003;9:1-8.

32. Karaman E, Yazıcı R, Gorucu J, Beseren M. Farklı pürüzlendirme yöntemleriyle uygulanan fissür örtücülerin 18 aylık klinik performanslarının değerlendirilmesi. Gazi Üniv Diş Hek Fak Derg 2012;29:33-40.

33. Ramos TM, Ramos-Oliveira TM, Moretto SG, de Freitas PM, Esteves-Oliveira M, de Paula Eduardo C. Microtensile bond strength analysis of adhesive systems to Er:YAG and Er,Cr:YSGG laser-treated dentin. Lasers Med Sci 2014; 29:565-73.

34. Al-Rifaiy MQ. The effect of mechanical and chemical polishing techniques on the surface roughness of denture base acrylic resins. Saudi Dent J 2010;22:13-7

35. International Organization for Standardization. Specefication 1567: Denture base polymers (ed 2). Geneva, Switzerland, 1988, pp.1-9.

36. Machado AL, Breeding LC, Puckett AD. Effect of microwave disinfection on the hardness and adhesion of two resilient liners. J Prosthet Dent 2005;94:183-9.

37. Amin WM, Fletcher AM, Ritchie GM. The nature of the interface between polymethyl methacrylate denture base materials and soft lining materials. J Dent 1981;9:336-46.

38. Lawrance J, Li L. Modification of the wettability characteristics of polymethyl methacrylate (PMMA) by means of $\mathrm{CO}_{2}, \mathrm{Nd}$ : YAG, excimer and high power diode laser irradiation. Mater Sci Eng A 2001;303:142-9.

39. Delfino CS, Souza-Zaroni WC, Corona SA, PalmaDibb RG. Microtensile bond strength of composite resin to human enamel prepared using erbium: Yttrium aluminum garnet laser. J Biomed Mater Res A 2007;80:475-9.

\section{Yazışma Adresi:}

Yrd. Doç. Dr. Fatih Mehmet KORKMAZ

Karadeniz Teknik Üniversitesi

Diş Hekimliği Fakültesi

Protetik Diş Tedavisi A.D

Kanuni Kampüsü, 61080 Trabzon

Tel: 0462 3774700-4800

Fax: 04623253017

e-mail: fmkorkmaz@hotmail.com 